\title{
Robust Sliding Mode Control Using Adaptive Switching Gain for Induction Motors
}

\author{
K. Jamoussi ${ }^{1}$ \\ L. Chrifi-Alaoui ${ }^{2}$ \\ H. Benderradji ${ }^{3}$ \\ A. El Hajjaji ${ }^{4}$ \\ M. Ouali ${ }^{1}$ \\ ${ }^{1}$ Laboratory Computer and Embedded Systems, National Engineering School, University of Sfax, Tunisia \\ ${ }^{2}$ Laboratory of Innovative Technology, University of Picardie Jules Verne, Cuffies 02880, France \\ ${ }^{3}$ University of M'sila, Electrical Engineering Department, M'sila 28000, Algeria \\ ${ }^{4}$ Laboratory of Modeling, Information and Systems, University of Picardie Jules Verne, France
}

\begin{abstract}
A robust sliding mode approach combined with a field oriented control (FOC) for induction motor (IM) speed control is presented. The proposed sliding mode control (SMC) design uses an adaptive switching gain and an integrator. This approach guarantees the same robustness and dynamic performance of traditional SMC algorithms. And at the same time, it attenuates the chattering phenomenon, which is the main drawback in actual implementation of this technique. This approach is insensitive to uncertainties and permits to decrease the requirement for the bound of these uncertainties. The stability and robustness of the closedloop system are proven analytically using the Lyapunov synthesis approach. The proposed method attenuates the effect of both uncertainties and external disturbances. Experimental results are presented to validate the effectiveness and the good performance of the developed method.
\end{abstract}

Keywords: Sliding mode control, field oriented control (FOC), practical validation, switching gain, induction motor.

\section{Introduction}

Due to the advances in power electronics and microprocessors, induction motor (IM) drives used in variable speed and position control have become more attractive in industrial processes, such as robot manipulators, factory automations, and transportation applications. However, the dynamic characteristics of the induction motor drive are complex, highly nonlinear and coupled. In addition, the drive control is sensitive to machine parameter variations and load disturbances.

In the past years, many techniques for the control of IMs have been investigated. Among them, the field oriented control (FOC) is the most popular one. The availability of high-performance digital signal processors (DSPs) makes field oriented control a practical choice for a wide range of applications. The rotor flux orientation is generally preferred, owing to the obtained high dynamic and steadystate performance. Nevertheless, the control performance of the resulting system is still influenced by the uncertainties, which are usually composed of unpredictable parameter variations, external load disturbances and nonlinear dynamics. Therefore, many studies have been made on the motor drives in order to preserve the performance under these uncertainties ${ }^{[1-4]}$. For example, new nonlinear control approaches were proposed such as neural control ${ }^{[2,3]}$, fuzzy control ${ }^{[1,4]}$ and sliding mode control $(\mathrm{SMC})^{[5-8]}$.

In the last few years, the variable structure control strategy using the sliding mode has received much attention in the electrical drives control area ${ }^{[9-14]}$. The main objective is to close the dynamic system with a sliding surface. The most significant property of the sliding mode control (SMC) concerns its robustness, fast dynamic response and insensitivity to parameter variations ${ }^{[1-15]}$. Usually, the SMC has some intrinsic problems, such as discontinuous control that often yields chattering which may be considered a problem for implementing in some real applications. Recently, different methods have been suggested to reduce the chattering using the continuous approximation techniques such as the boundary layer ${ }^{[3,15-18]}$.

The aim of this paper is to develop a nonlinear sliding mode control law which incorporates an adaptive switching gain according to a sliding surface, angular speed and its derivative. An improvement of this method was verified by a practical implementation with comparison between sigmoid function, relay function and hyperbolic tangent function.

However, the use of classical SMC approach via an adaptive switching gain permits to reduce chattering phenomenon but leads to a steady-state error created by disturbance. Then, we added an integral action when the trajectories of states approach their references to eliminate this steady-state error ${ }^{[19-22]}$. The proposed algorithm provides better convergence than those proposed in the literatures while keeping the robustness properties. We used this approach to control the speed and flux of an induction motor.

The implementation of this algorithm requires the real time availability of the time-derivatives of the speed. To do this, we use a robust differentiator via the sliding mode ${ }^{[7]}$ which is applied to angular speed measurements. Experimental results are presented to validate the effectiveness and the good performance of the developed method.

The paper is organized as follows. In Section 2, we present the model of IM. Section 3 is devoted to the nonlinear sliding mode control where the robust speed control design uses an adaptive switching gain and integrator. The experimental results are presented in Section 4. Section 5 draws the conclusions. 


\section{Induction motor model}

The dynamic equation of an IM in a synchronous reference frame is ${ }^{[16]}$

$$
\left\{\begin{array}{l}
\dot{\psi}_{d r}=-\frac{1}{\tau_{r}} \psi_{d r}+\omega_{r} \psi_{q r}+\frac{L_{m}}{\tau_{r}} I_{d s} \\
\dot{\psi}_{q r}=-\omega_{r} \psi_{d r}-\frac{1}{\tau_{r}} \psi_{q r}+\frac{L_{m}}{\tau_{r}} I_{q s} \\
\dot{I}_{d s}=\frac{\alpha}{\tau_{1} L_{1}} \psi_{d r}+\frac{\alpha}{L_{1}} p \omega_{m} \psi_{q r}-\frac{1}{\tau_{1}} I_{d s}+\omega_{s} I_{q s}+\frac{1}{L_{1}} V_{d s} \\
\dot{I}_{q s}=-\frac{\alpha}{L_{1}} p \omega_{m} \psi_{d r}+\frac{\alpha}{\tau_{1} L_{1}} \psi_{q r}-\omega_{s} I_{d s}-\frac{1}{\tau_{1}} I_{q s}+\frac{1}{L_{1}} V_{q s} \\
\dot{\omega}_{m}=\frac{p}{J}\left[\alpha\left(\psi_{d r} I_{q s}-\psi_{q r} I_{d s}\right)-T_{m}\right]
\end{array}\right.
$$

where $V_{d s}$ and $V_{q s}$ are the stator voltage components, $I_{d s}$ and $I_{q s}$ are the stator current components, and $\psi_{d r}$ and $\psi_{q r}$ are the rotor flux components.

And $\omega_{r}=\omega_{s}-p \omega_{m}, L_{1}=L_{s}-\alpha L_{m}, \alpha=\frac{L_{m}}{L_{r}}, \tau_{r}=\frac{L_{r}}{R_{r}}$, $\tau_{1}=\frac{L_{1}}{R_{1}}, R_{1}=R_{s}+\alpha^{2} R_{r}$, where $R_{r}$ and $R_{s}$ are the rotor and stator resistances, $L_{r}$ and $L_{s}$ are the rotor and stator inductances, $L_{m}$ is the mutual inductance, $p$ is the number of pairs of poles, $\omega_{r}, \omega_{s}$ and $\omega_{m}$ are the slip speed, electrical synchronous speed and rotor speed, $T_{m}$ is a load torque, and $J$ is the inertia.

Conventionally, the $d$-axis is the magnetising axis and $q$-axis is the torque axis, so we can write the following expressions $^{[6]}$ :

$$
\left\{\begin{array}{l}
\psi_{d r}=\psi_{d} \\
\psi_{q r}=0 .
\end{array}\right.
$$

Then, the rotor flux is oriented to the $d$-axis. This orientation leads to the decoupling between flux and torque, resulting in a linear and decoupled machine control, an optimal developed machine control and an optimal developed torque $^{[15]}$.

Thus, $\psi_{q r}=0$ or $\dot{\psi}_{q r}=0$ with $\psi_{q r}(0)=0$. This allows eliminating the terms $\psi_{q r}$ in (1), which reduces the model order to four. Indeed, the second state equation of system (1) becomes

$$
\omega_{s}=p \omega_{m}+\frac{L_{m} I_{q s}}{\tau_{r} \psi_{d r}} .
$$

This gives the expression of the stator pulsation according to the variables of states. Then, the state space equations become

$$
\left\{\begin{array}{l}
\dot{\psi}_{d r}=-\frac{1}{\tau_{r}} \psi_{d r}+\frac{L_{m}}{\tau_{r}} I_{d s} \\
\dot{I}_{d s}=\frac{\alpha}{\tau_{1} L_{1}} \psi_{d r}-\frac{1}{\tau_{1}} I_{d s}+\omega_{s} I_{q s}+\frac{1}{L_{1}} V_{d s} \\
\dot{I}_{q s}=-\frac{\alpha}{L_{1}} p \omega_{m} \psi_{d r}-\omega_{s} I_{d s}-\frac{1}{\tau_{1}} I_{q s}+\frac{1}{L_{1}} V_{q s} \\
\dot{\omega}_{m}=\frac{p}{J}\left[\alpha \psi_{d r} I_{q s}-T_{m}\right] .
\end{array}\right.
$$

\section{Control design}

\subsection{Sliding mode control}

The drawback of the classical sliding mode control is the well-known chattering phenomenon, which may excite unmodeled high-frequency modes and can also lead to high deterioration of moving mechanical parts and high heat losses in electrical power circuits.
The sliding mode controller was designed to operate over the same variables used in the FOC method. The main objective of this approach is to obtain a sliding mode controller with all the qualities of FOC, which calculates the optimal stator voltage vector to maintain the stator winding linkage flux magnitude and speed within the desired ranges ${ }^{[19]}$.

In general, the design procedure of the sliding mode control technique can be divided into two steps. In the first step, we can design a switching surface. Such system response in the sliding mode has the desired properties. The second step, is to design the control law to achieve the reaching condition for a sliding mode to be achieved in a finite time.

\subsection{Flux regulation}

Considering the first and second equalities of system (3), we can obtain the expressions as

$$
\begin{aligned}
& \dot{\psi}_{d r}=-\frac{1}{\tau_{r}} \psi_{d r}+\frac{L_{m}}{\tau_{r}} I_{d s} \\
& \dot{I}_{d s}=\frac{\alpha}{\tau_{1} L_{1}} \psi_{d r}-\frac{1}{\tau_{1}} I_{d s}+\omega_{s} I_{q s}+\frac{1}{L_{1}} V_{d s} .
\end{aligned}
$$

For simplicity, we define the following flux error:

$$
e_{f}=\psi_{d r}-\psi_{d r_{-} r e f}
$$

where $\psi_{d r_{-} \text {ref }}$ is the flux magnitude reference and $\psi_{d r}$ is estimated from the measured value of $I_{d s}$ by using the first equality of (4).

The sliding mode flux surface is defined as

$$
S_{f}=c_{1} e_{f}+\dot{e}_{f} .
$$

Taking the derivative of the previous equality by substituting the first equality of (4) with $\psi_{d r_{-} r e f}=$ constant, we obtain

$$
\begin{aligned}
& \dot{S}_{f}=c_{1} \dot{e}_{f}+\ddot{e}_{f}= \\
& c_{1} \dot{\psi}_{d r}+\ddot{\psi}_{d r}= \\
& \quad\left(c_{1}-\frac{1}{\tau_{r}}\right)\left(-\frac{1}{\tau_{r}} \psi_{d r}+\frac{L_{m}}{\tau_{r}} I_{d s}\right)-\frac{1}{\tau_{r}} \dot{\psi}_{d r}+\frac{L_{m}}{\tau_{r}} \dot{I}_{d s} .
\end{aligned}
$$

By substituting $\dot{\psi}_{d r}$ and $\dot{I}_{d s}$ from (3) into (6), we obtain

$$
\begin{aligned}
\dot{S}_{f}= & \left(c_{1} \frac{1}{\tau_{r}}-\frac{1}{\tau_{r}^{2}}+\frac{L_{m} \alpha}{\tau_{r} \tau_{1} L_{1}}\right) \psi_{d r}+ \\
& \left(c_{1}-\frac{1}{\tau_{r}}-\frac{1}{\tau_{1}}\right) \frac{L_{m}}{\tau_{r}} I_{d s}+U_{f}
\end{aligned}
$$

where $U_{f}=\frac{L_{m}}{\tau_{r}}\left(\omega_{s} I_{q s}+\frac{1}{L_{1}} V_{q s}\right)$ is the new control function.

In order to obtain the so-called equivalent control $u_{f e q}$, we can resolve (6) and obtain

$$
\begin{aligned}
u_{f e q}=- & \left(c_{1} \frac{1}{\tau_{r}}-\frac{1}{\tau_{r}^{2}}+\frac{L_{m} \alpha}{\tau_{r} \tau_{1} L_{1}}\right) \psi_{d r}- \\
& \left(c_{1}-\frac{1}{\tau_{r}}-\frac{1}{\tau_{1}}\right) \frac{L_{m}}{\tau_{r}} I_{d s} .
\end{aligned}
$$

The function $\Delta U_{f}$ is the discontinuous term employed to eliminate the influence of the uncertainties, which are usually composed of unpredictable parameter variations, external load disturbances, unmodelled and nonlinear dynamics, 
etc. $\Delta U_{f}$ can be represented as

$$
\Delta U_{f}=-K_{f} \operatorname{sgn}\left(S_{f}\right) .
$$

\subsection{Speed regulation}

The equations used for angular speed regulating are written as

$$
\begin{aligned}
& \dot{I}_{q s}=-\frac{\alpha}{L_{1}} p \omega_{m} \psi_{d r}-\omega_{s} I_{d s}-\frac{1}{\tau_{1}} I_{q s}+\frac{1}{L_{1}} V_{q s} \\
& \dot{\omega}_{m}=\frac{p}{J}\left[\alpha \psi_{d r} I_{q s}-T_{m}\right] .
\end{aligned}
$$

From the second equality of (10), we can write

$$
I_{q s}=\frac{T_{m}}{\alpha \psi_{d r}}+\frac{J \dot{\omega}_{m}}{p \alpha \psi_{d r}} .
$$

The elimination of the state variable $I_{q s}$ gives the following differential equation in $\omega_{m}$ :

$$
\begin{aligned}
& \ddot{\omega}_{m}=\frac{p}{J}\left[\alpha \psi_{d r} \dot{I}_{q s}-\dot{T}_{m}\right]= \\
& \frac{p}{J}\left[\alpha \psi_{d r}\left(-\frac{\alpha}{L_{1}} p \omega_{m} \psi_{d r}-\omega_{s} I_{d s}-\frac{1}{\tau_{1}} I_{q s}+\frac{1}{L_{1}} V_{q s}\right)-\dot{T}_{m}\right]= \\
& -\frac{1}{\tau_{1}} \dot{\omega}_{m}-\frac{\alpha^{2}}{L_{1}} p \psi_{d r}^{2} \omega_{m}-\frac{p}{J \tau_{1}} T_{m}-\frac{p}{J} \dot{T}_{m}+u_{v} .
\end{aligned}
$$

We note that the mechanical load torque $T_{m}$ is assumed to be a slowly varying function of time

$$
\ddot{\omega}_{m}=-A \dot{\omega}_{m}-B \omega_{m}-C+u_{v}
$$

where $u_{v}=\frac{\alpha}{J L_{1}} p \psi_{d r} V_{q s}-\frac{\alpha}{J} p \psi_{d r} \omega_{s} I_{d s}$ represents the control input, $A=-\frac{1}{\tau_{1}}, B=-\frac{\alpha^{2}}{L_{1}} p \psi_{d r}^{2}$, and $C=-\frac{p}{J \tau_{1}} T_{m}-$ $\frac{p}{J} \dot{T}_{m}$.

The error on the angular speed is written as

$$
\begin{aligned}
& e_{v}=\omega_{m}-\omega_{r e f} \\
& S_{v}=c_{2} e_{v}+\dot{e}_{v}
\end{aligned}
$$

where $c_{2}$ is a positive constant.

The derivative of (14) can be written as

$$
\begin{aligned}
\dot{S}_{v}= & c_{2} \dot{e}_{v}+\ddot{e}_{v}= \\
& c_{2}\left(\dot{\omega}_{m}-\dot{\omega}_{r e f}\right)+\left(\ddot{\omega}_{m}-\ddot{\omega}_{r e f}\right) .
\end{aligned}
$$

The equivalent control $U_{v e q}$ is defined by

$$
u_{v e q}=-\left(c_{2}-A\right) \dot{\omega}_{m}+B \omega_{m}+C+c_{2} \dot{\omega}_{r e f}+\ddot{\omega}_{r e f} .
$$

And the discontinuous control is

$$
\Delta u_{v}=-\left(K_{v}\right) \operatorname{sgn}\left(S_{v}\right) .
$$

To satisfy more performance with the sliding mode controller, we must choose a large value of $K_{v}$. But a larger value of $K_{v}$ may lead to more chattering of the control variable and system states. A boundary layer of definite width on both sides of switching line is introduced to reduce chattering.
We know that sliding mode techniques can generate undesirable chattering. To eliminate the chattering phenomenon, we replace a discontinuous signum function by a smooth function like sigmoid function or saturation function sat $(S)$ or hyperbolic tangent function $\operatorname{tgh}(S)$. Consequently, the robustness will decrease.

The chattering problem is overcome using a hyperbolic function for the sliding surface. To eliminate the chattering without losing the robustness, the gain $K_{v}$ was replaced by

$$
K_{v}=K_{1} \dot{\omega}_{m}+K_{2} \omega_{m}+K_{3}\left|S_{v}\right| .
$$

It should be noted that our proposition is used to overcome the undesirable chattering. By using this function, the switching gain is adapted according to $S_{v}, \omega_{m}$ and $\dot{\omega}_{m}$. The switching gain is adapted using a simple algorithm which does not imply a high computational load.

Note that the better choices of $K_{1}, K_{2}$ and $K_{3}$ allow to satisfy the sliding condition $S_{v} \dot{S}_{v}<0$.

\subsection{Robust differentiator}

In the experiment tests, it is known that the derivation of the angular speed using Matlab block differentiator may generate the accurate derivative and some high frequency noise.

In this section, a robust differentiator via sliding mode technique is studied. Indeed, a robust exact differentiation via sliding mode technique was proposed in [20]. The differentiator considered features of simple form and easy design. It was synthesized to be employed in real-time control systems.

Without lost of generality, let the input signal $f(t)$ be a measurable function and let it consist of a base signal having a derivative with Lipschitz's constant $C>0$. In order to differentiate the input signal, consider the auxiliary equality

$$
\dot{x}=u \text {. }
$$

Consider the following sliding surfaces which represent the difference between $x$ and $f(t)$ :

$$
s=x-f(t) .
$$

By differentiating $s$, we obtain the relationship

$$
\dot{s}=u-\dot{f}(t) .
$$

The super twisting algorithm defines the control law $u$ as

$$
u=u_{1}-\lambda|s|^{\frac{1}{2}} \operatorname{sgn}(s)
$$

where $u_{1}=-w \operatorname{sgn}(s), \lambda, w>0$, and $u$ is the output of the differentiator.

Indeed, the super twisting algorithm converges in a finite time, so the following relationship can be obtained in a finite time:

$$
\dot{x}-\dot{f}(t)=u-\dot{f}(t)=0
$$

or

$$
u=\dot{f}(t) .
$$

The corresponding sufficient conditions for a finite time convergence are

$$
\begin{aligned}
& w>C \\
& \lambda^{2} \geqslant 4 C \frac{w+C}{w-C} .
\end{aligned}
$$


Fig. 1 presents the structure of the differentiator ${ }^{[23]}$. The separation principle is fulfilled for the proposed differentiator. A combined differentiator-controller output feedback preserves the main features of the controller with the full state available ${ }^{[24]}$.

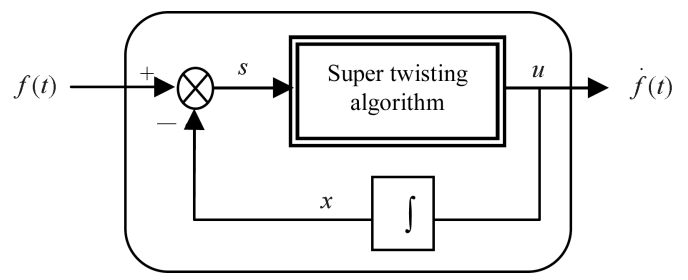

Fig. 1 Structure of the differentiator

\subsection{Interpolation of the integrator con- troller}

In this section, our object is to reconstitute a control law to eliminate the speed steady-state error creation by disturbance. We propose to insert an integrator when the trajectory of state approaches its reference ${ }^{[21]}$.

$$
U_{v}=\left\{\begin{array}{l}
U_{v e q}+\Delta U_{v}, \quad \text { if }\left\|\omega_{r e f}-\omega_{m}\right\|>\delta \\
U_{v e q}+\Delta U_{v}+U_{i n t}, \quad \text { if }\left\|\omega_{r e f}-\omega_{m}\right\|<\delta
\end{array}\right.
$$

where

$$
U_{i n t}=-k_{v} \int e_{v} \mathrm{~d} t
$$

$k_{v}$ is the integral constant.

\section{Simulation and experimental results}

The Simulink/Matlab software package implementation was adopted because of its inherent integration of vectorized system representations. Moreover, the simulation provides valuable information about the dynamic behavior of the plant. The proposed approach has been simulated using the induction motor with the following parameters as shown in Table 1.

Table 1 Motor parameters

\begin{tabular}{cc}
\hline Parameters & Value \\
\hline$R r$ & $4.2 \Omega$ \\
$R s$ & $5.72 \Omega$ \\
$L r$ & $461 \mathrm{mH}$ \\
$L s$ & $462 \mathrm{mH}$ \\
$L m$ & $460 \mathrm{mH}$ \\
$J$ & $0.015 \mathrm{~kg} \cdot \mathrm{m}^{2}$ \\
$P$ & 2 Pair of poles \\
Power & $1500 \mathrm{~W}$ \\
\hline
\end{tabular}

Typical test simulations of a speed induction motor control include an internal parameter variation.

A periodic trapezoidal reference speed is used here to study the tracking performance of the drive system. The speed profile is increased linearly to $50 \mathrm{rad} / \mathrm{s}$ during $3 \mathrm{~s}$. It is kept constant at $50 \mathrm{rad} / \mathrm{s}$ till $t=8.5 \mathrm{~s}$, and decreased linearly to $0 \mathrm{rad} / \mathrm{s}$ at $t=11.5 \mathrm{~s}$, then kept constant at $0 \mathrm{rad} / \mathrm{s}$ for $1 \mathrm{~s}$. Then it is decreased linearly to $-50 \mathrm{rad} / \mathrm{s}$ at $t=15.5 \mathrm{~s}$. It is kept constant at $-50 \mathrm{rad} / \mathrm{s}$ till $t=20.5 \mathrm{~s}$. After that, it is increased linearly to $0 \mathrm{rad} / \mathrm{s}$ at $t=23.5 \mathrm{~s}$.

In the following test, we use the classical discontinuous control defined by

$$
\Delta u=-K \operatorname{sgn}(S)
$$

where $K$ is a positive constant.

The rotor speed and stator voltage are illustrated in Figs. 2 and 3.

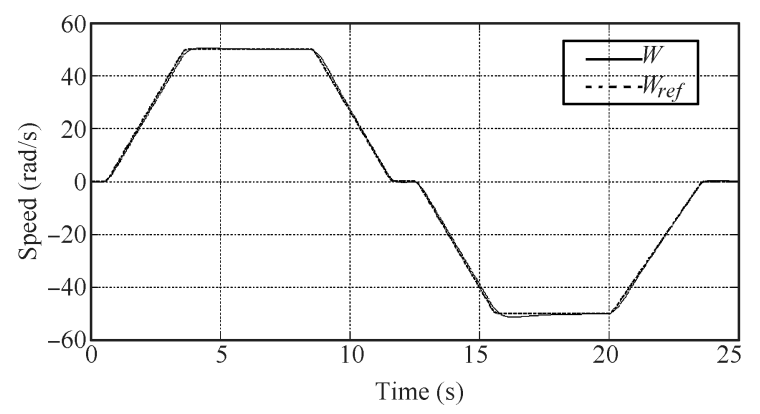

Fig. 2 Behavior of speed rotor (measured and reference)

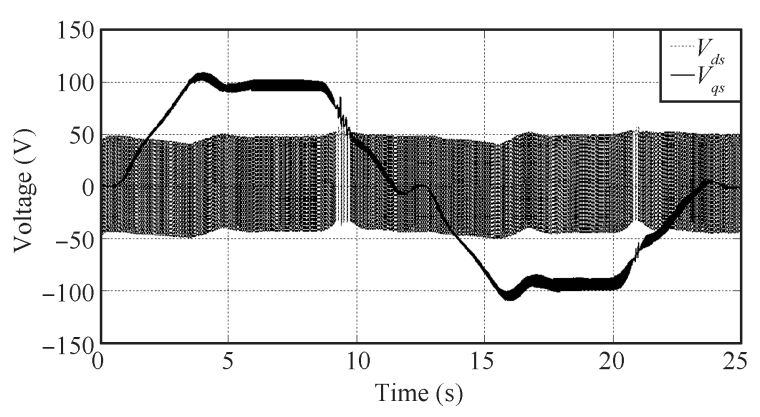

Fig. 3 Behavior of stator voltage

In order to avoid chattering problem and noise disturbances, we used a proposed discontinuous control described in (18). The behavior of speed in the closed loop without the integrator controller is illustrated in Fig. 4. In Fig. 3, rotor flux of a $d$-component is shown. Fig. 5 shows the best flux tracking and robustness for the change of speed reference.

The behaviors of two components stator voltages are presented in Fig. 6.

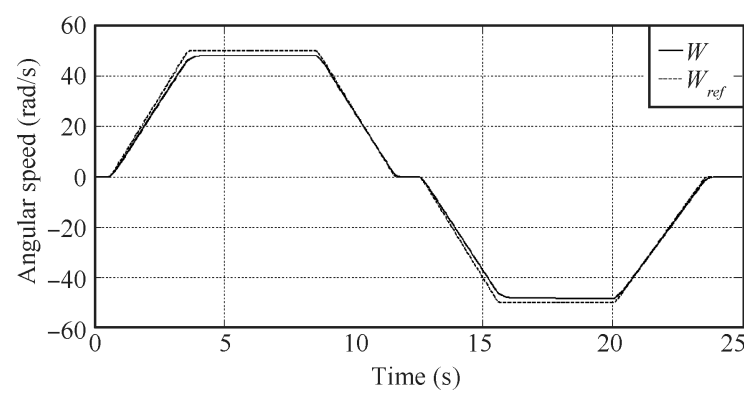

Fig. 4 Behavior of speed rotor (measured and reference) 


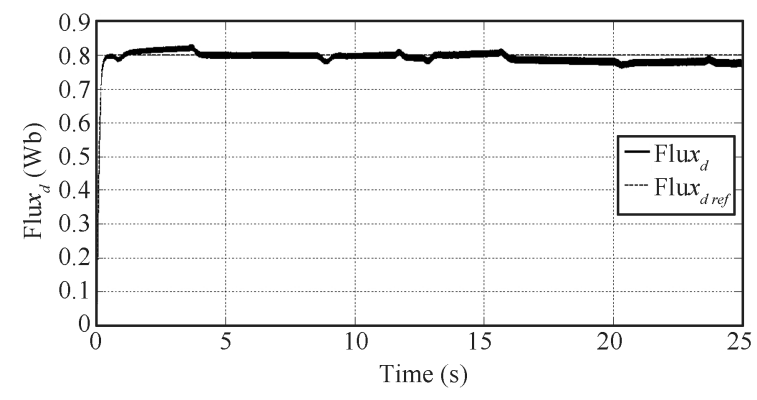

Fig. 5 Magnitude flux

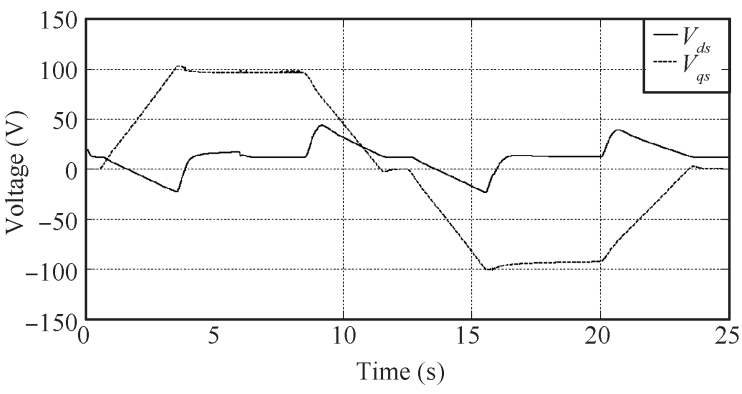

Fig. 6 Stator voltages $\left(V_{d s}\right.$ and $\left.V_{q s}\right)$

To eliminate speed steady-state error creation by disturbance, we inserted an integrator control.

Fig. 7 shows the behavior of the angular speed with integrator component. It demonstrates that the convergence of the speed was achieved.

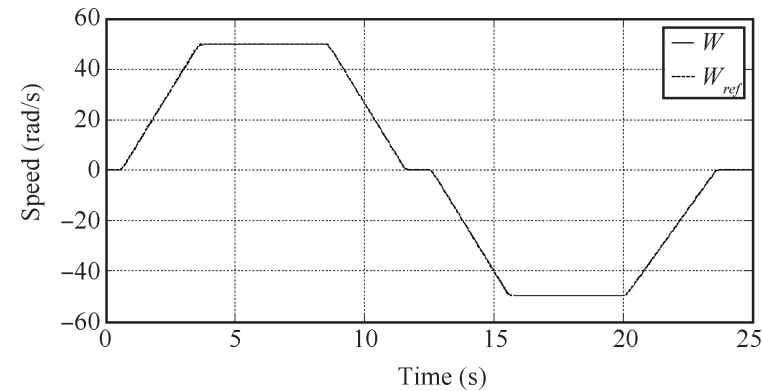

Fig. 7 Angular speed with integrator component

After the simulation tests and in order to verify the performance of the proposed method, the experimental activities were carried out using the benchmark presented in Fig. 8. It includes electronic circuits and electro-mechanical devices. Figs. 9-11 display the built experimental setup during the development phase.

The motor nameplate is presented in Fig. 12.

The experimental benchmark consists of a dSpace board (DS1104) connected to a three-phase inverter by an adapter card in order to drive a $1.5 \mathrm{~kW}$ induction motor. The dSpace board operates with a $0.1 \mathrm{~ms}$ sampling period and the pulse width modulation (PWM) worked at $5 \mathrm{kHz}$. At each sampling instant, the dSpace board receives the measured current and actual position through the current transducer board and a 5000 points incremental encoder.

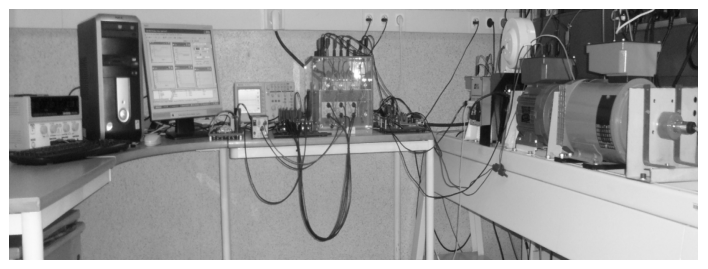

Fig. 8 The benchmark used in the experiment tests (IUT Soissons-France)

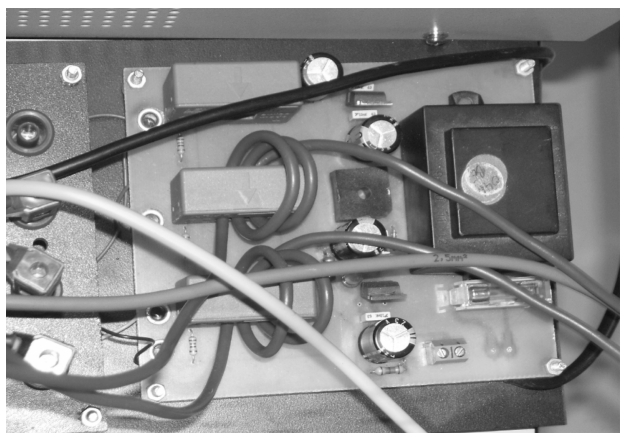

Fig. 9 Current transducer board

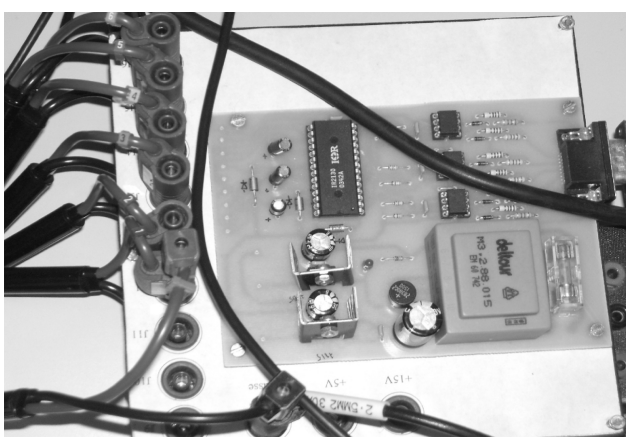

Fig. 10 Adaptor electronic card

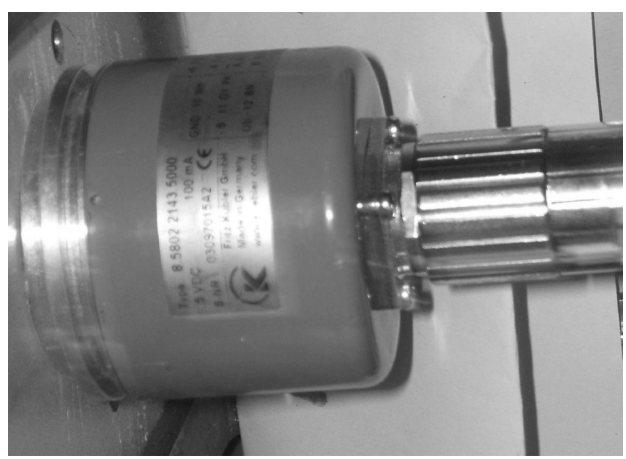

Fig. 11 The position incremental encoder

The torque load is a powder brake. It is used to create external disturbances in order to verify the robustness of our approach. The conditioning signal board is necessary to acquire the motor state variables from a high level of current to an appropriate voltage level. 


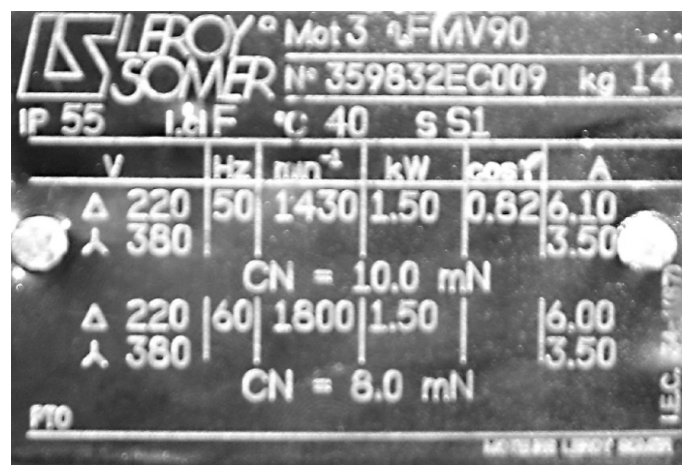

Fig. 12 Motor nameplate

The different tests for the sliding mode controller combined with the field orientation principle of induction motor have proven the improvement made by our approach by comparison with the classical switching gain.

To prove the performance of the proposed function for the different speed conditions, several tests are performed and the results are shown in Figs. 13-24.

Both the sign and the relay functions do not perform accurately in a discrete-time system and the practical test, resulting in oscillation and undesired chattering. This undesirable chattering can deteriorate the inverter electronics components.

With the discontinuous control described by (17), it was clear that the stator voltage component $V_{d s}$ may give rise to chattering. In this case, we may risk destroying the motor and the inverter arms. For this reason, we did not take this experiment.

The first test was performed in order to test the efficiency of the proposed method and evaluate the performance and stability of the system. We used the sliding control mode using the discontinuous control described as

$$
\Delta U_{v}=-K_{v} \operatorname{sat}\left(S_{v}\right)
$$

Figs. 13 and 14 present the time evolution of the angular speed with its reference and the behaviors of the stator voltage, respectively.

The oscillations, usually referred to as chattering, are known to result in a low control accuracy, high heat losses in the electrical power circuits, and high wear of moving mechanical parts. These phenomena have been considered as serious obstacles for applications of the sliding-mode control.

Despite the use of saturation function, the stator voltage presents undesirable oscillations that lose robustness.

Fig. 15 shows the evolution of the measured angular speed and its reference using the discontinuous control described by (18) and without interpolation of the integrator controller.

Figs. 16-18 show the evolutions of $I_{d s}$ current, the rotor flux magnitude $\left(\psi_{d r_{-} r e f}\right.$ and $\left.\psi_{d r}\right)$ and the stator voltages $\left(V_{d s}\right.$ and $\left.V_{q s}\right)$, respectively.

It should be noted that the adaptive sliding gain allows employing a smaller sliding gain, so that the value of the sliding gain does not have to be chosen high enough to compensate for all the possible system uncertainties.

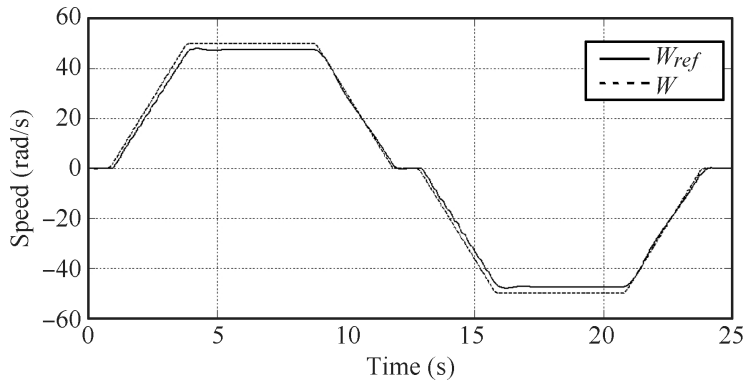

Fig. 13 Angular speed (measured and reference)

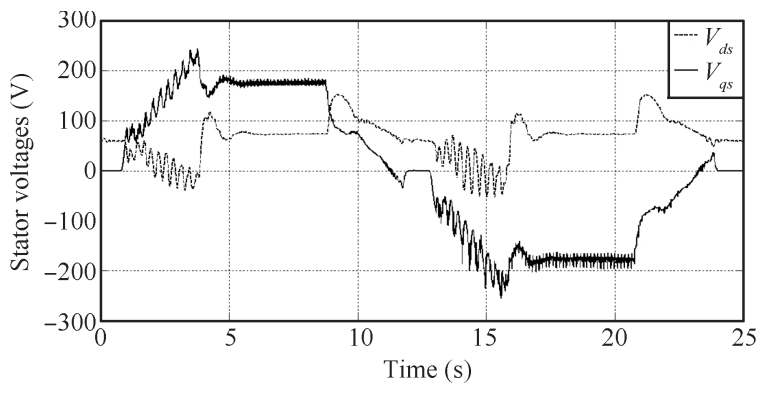

Fig. 14 Stator voltages

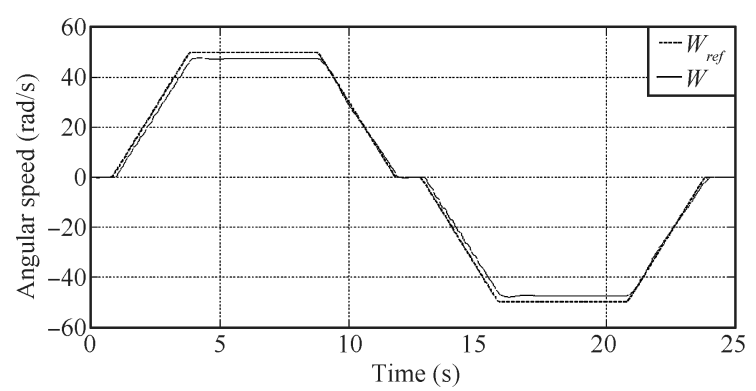

Fig. 15 Real and reference speeds with sliding mode controller

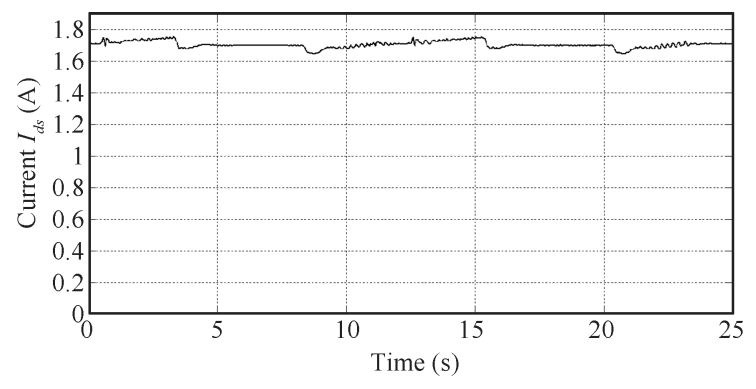

Fig. 16 Behavior of current $I_{d s}$

As can be seen from this experimental result, the speed steady-state error was about $3 \mathrm{rad} / \mathrm{s}$ as show in Fig. 15.

In Fig. 17, high flux tracking and good rotor flux orientation can be observed.

In order to overcome the speed steady-state error, we introduced the integrator controller. We noticed that the error made in the speed converged to zero as shown in Fig. 19.

Fig. 19 shows the speed response of the motor, i.e., a very 
good speed regulation is obtained. One can see that the obtained speed results are satisfactory and the oscillations are minimal.

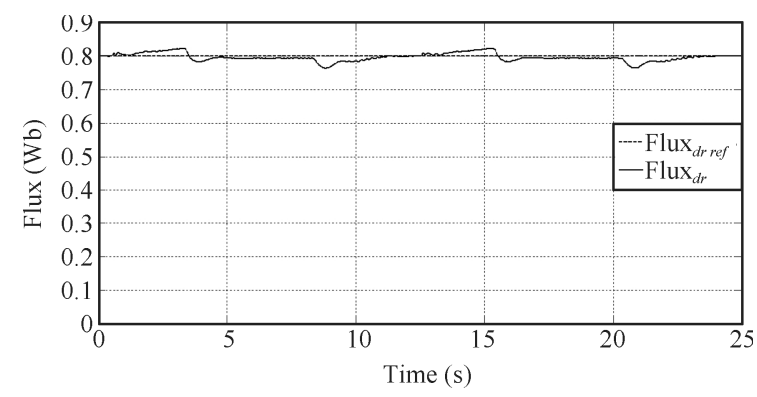

Fig. 17 Estimated and reference $d$-axis rotor flux

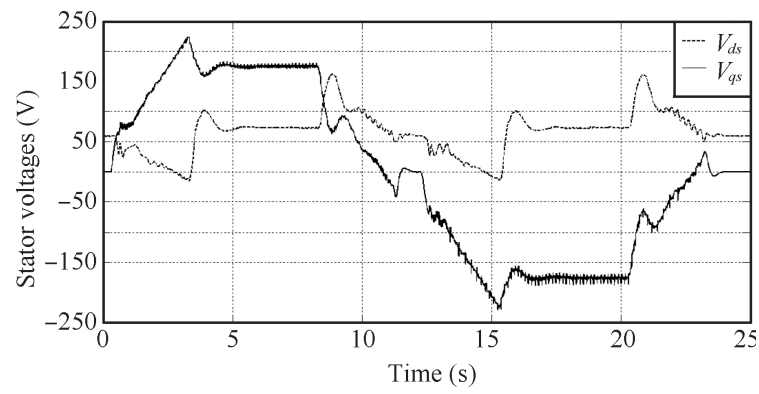

Fig. 18 Stator voltages

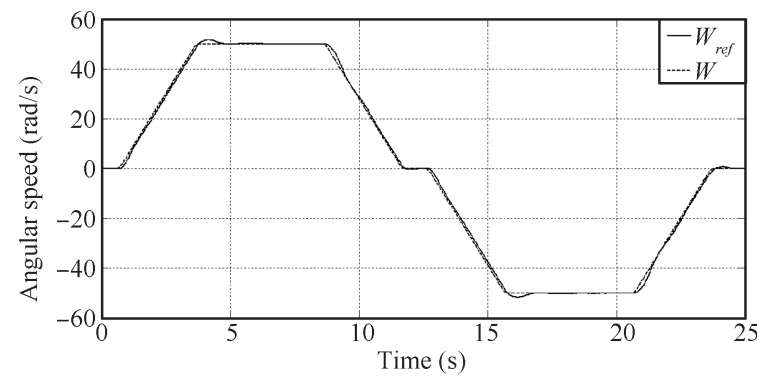

Fig. 19 Real speed and reference speed with sliding mode and integrator controller

As can be seen from this experimental result, the proposed algorithm is very robust and reliable for any speed condition.

In the same way, we applied the same condition for high speed control. In Fig. 20, the speed profile is increased linearly to $150 \mathrm{rad} / \mathrm{s}$ during $3 \mathrm{~s}$. It is kept constant at $150 \mathrm{rad} / \mathrm{s}$ till $t=8.2 \mathrm{~s}$, decreased linearly to $0 \mathrm{rad} / \mathrm{s}$ at $t=11.2 \mathrm{~s}$, and kept constant at $0 \mathrm{rad} / \mathrm{s}$ for $1 \mathrm{~s}$. Then it is decreased linearly to $-150 \mathrm{rad} / \mathrm{s}$ at $t=15.5 \mathrm{~s}$. It is kept constant at $-150 \mathrm{rad} / \mathrm{s}$ till $t=17 \mathrm{~s}$.

To test the robustness of the proposed method, we introduced change on the load torque applied on the shaft motor between $9 \mathrm{~s}$ and $14 \mathrm{~s}$.

Fig. 22 shows the desired and real rotor speeds. As may be observed, the sliding mode control is very robust to external load disturbances.

Figs. 23 and 24 show the responses stator voltage and the rotor flux magnitude during variation of load torque, respectively.

These results show that the proposed sliding mode control can track the reference command accurately and quickly.

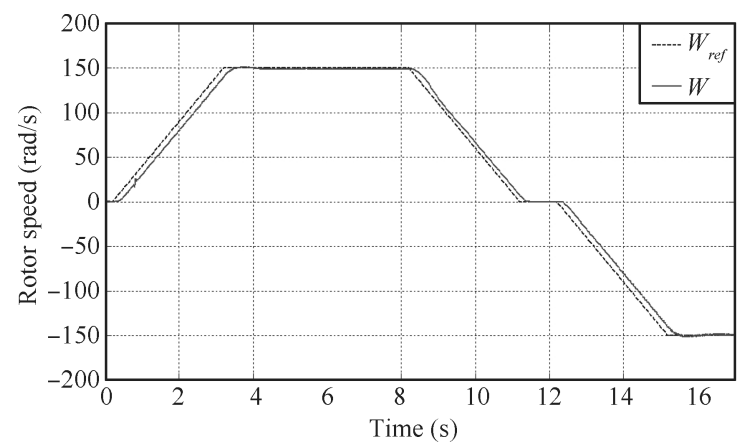

Fig. 20 Angular speeds (measured and reference)

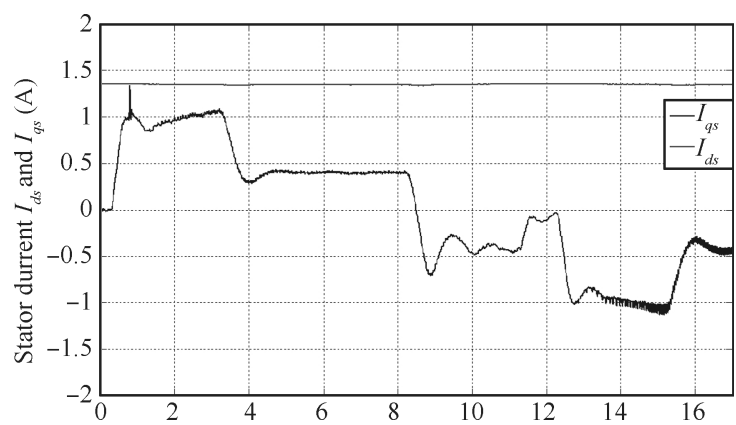

Fig. 21 Behaviors of $I_{d s}$ and $I_{q s}$ currents

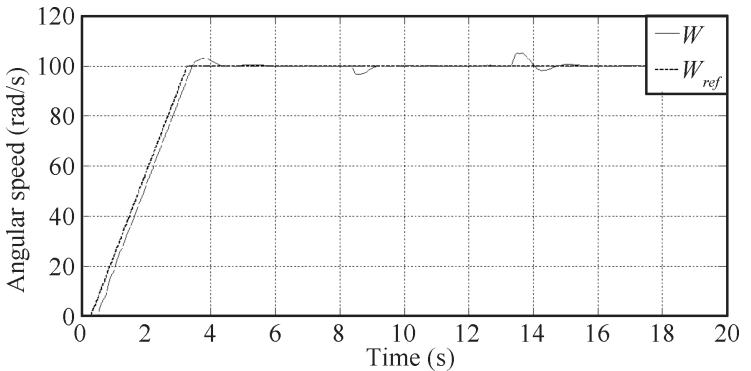

Fig. 22 Robustness test

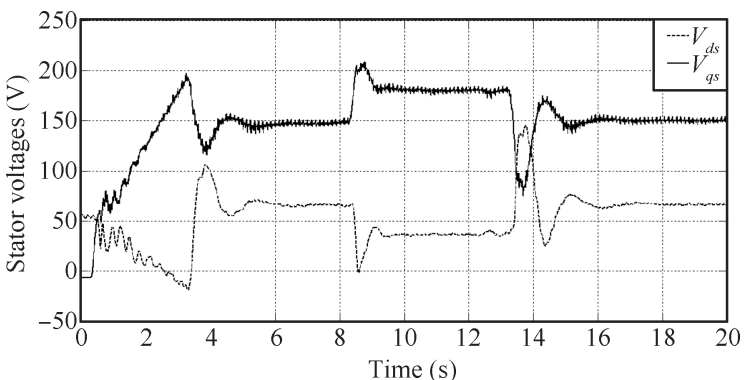

Fig. 23 Stator voltages 


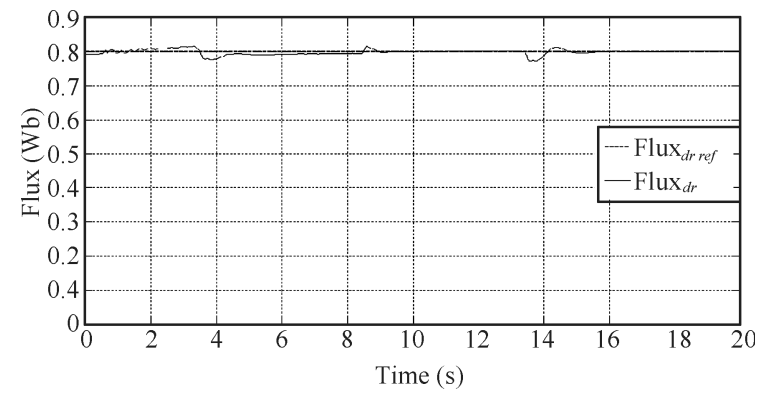

Fig. 24 Estimated and reference $d$-axis rotor flux

\section{Conclusions}

The robust sliding mode speed control has been developed to control the induction motor.

This technique is realized with rotor field orientation in the synchronous reference frame. The main objective of this work is to compensate the disturbance effect that happens from change of torque and incertitude of electrical parameter due to temperature and saturation.

A robust sliding mode speed control was employed to obtain the better performance in practical validation from the induction motor. Some simulation and experimental results under various operating conditions were provided to illustrate the effectiveness and robustness of the developed methodology.

The efficiency of the robust sliding mode control presented in this paper has been successfully verified by simulation. The proposed algorithm demonstrated very good performance. Especially, it is robust under rotor resistance variation, external load disturbances and speed tracking. This study was successfully implemented on a DSPACE1104 card, in the Laboratory of Innovative Technology, University of Picardie Jules Verne, France in order to overcome the external disturbances and parameter variations for the rotor speed control of an IM drive.

It is shown through all the achieved experimental results that the proposed technique gives good performance for the speed regulation of induction and confirm good robustness of the controlled system.

\section{References}

[1] A. Hazzab, A. Laoufi, I. K. Bousserhane, M. Rahli. Real time implementation of fuzzy gain scheduling of PI controller for induction machine control. International Journal of Applied Engineering Research, vol. 1, no. 1, pp.51-60, 2006 .

[2] L. Barazane, M. Laribi, M. M. Krishan, R. Ouiguini. A new Gaussian radial basis function neural network controller for induction motor control drives. In Proceedings of the 18th Mediterranean Conference on Control \& Automation, IEEE, Marrakech, Morocco, pp. 545-550, 2010.

[3] M. Ben Hamed, L. Sbita. Neural network speed controller for direct vector control of induction motors. International Journal of Engineering Science and Technology, vol. 2, no. 12 , pp. $7470-7480,2010$.

[4] M. Allouche, M. Chaabane, M. Souissi, D. Mehdi, F. Tadeo. State feedback tracking control for indirect field-oriented induction motor using fuzzy approach. International Journal of Automation and Computing, vol. 10, no. 2, pp. 99-110, 2013.

[5] M. Abid, A. Aaissaoui. Fuzzy sliding mode control of an induction motor. Acta Electrotechnica, vol. 49, no. 2, pp. 138146, 2008.

[6] M. K. A. Rosa, Soebagio, M. H. Purnomo. Induction motor speed control using fuzzy sliding mode controller based on direct field oriented control. In Proceedings of the 4th International Student Conference on Advanced Science and Technology, Izmir, Turkey, pp. 271-272, 2010.

[7] O. Barambones, A. J. Garrido, F. J. Maseda, P. Alkorta. An adaptive sliding mode control law for induction motors using field oriented control theory. In Proceedings of the IEEE International Conference on Control Applications, IEEE International Symposium on Intelligent Control, Computer Aided Control System Design, IEEE, Munich, Germany pp. 1008-1013, 2006.

[8] B. Bandyopadhyay, A. G/E. Alber, S. Janardhanan, V. Sreeram. Sliding mode control design via reduced order model approach. International Journal of Automation and Computing, vol. 4, no. 4, pp. 329-334, 2007.

[9] V. I. Utkin, J. Guldner, J. X. Shi. Sliding Mode Control in Electromechanical Systems, London: Taylor and Francis, 1999.

[10] W. Perruquetti, J. P. Barbot. Sliding Mode Control in Engineering, USA: CRC Press, 2002.

[11] V. I. Utkin. Sliding mode control design principles and applications to electric drives. IEEE Transactions on Industrial Electronics, vol. 40, no. 1, pp. 23-36, 1993.

[12] T. J. Fu, W. F. Xie. A novel sliding-mode control of induction motor using space vector modulation technique. ISA Transactions, vol. 44, no. 4, pp. 481-490, 2005.

[13] K. K. Shyu, H. J. Shieh. A new switching surface slidingmode speed control for induction motor drive systems. IEEE Transactions on Power Electronics, vol.11, no. 4, pp. 660-667, 1996.

[14] H. Benderradji, A. Makouf, L. Chrifi-Alaoui. Field-oriented control using sliding mode linearization technique for induction motor. In Proceedings of the 18th IEEE Mediterranean Conference on Control \& Automation, IEEE, Marrakech, Morocco, pp. 1133-1138, 2010.

[15] A. Mezouar, M. K. Fellah, S. Hadjeri. Robust sliding mode control and flux observer for induction motor using singular perturbation. Electrical Engineering, vol. 89, no. 3, pp. 193203, 2007.

[16] K. Jamoussi, M. Ouali, H. Charradi. A sliding mode speed control of an induction motor. American Journal of Applied Sciences, vol. 4, no. 12, pp. 987-994, 2007.

[17] M. M. M. Negm, J. M. Bakhashwain, M. H. Shwehdi. Speed control of a three-phase induction motor based on robust optimal preview control theory. IEEE Transactions on Energy Conversion, vol. 21, no. 1, pp. 77-84, 2006.

[18] H. Y. Zhou, K. Z. Liu, X. S. Feng. State feedback sliding mode control without chattering by constructing Hurwitz matrix for AUV movement. International Journal of $\mathrm{Au}$ tomation and Computing, vol. 8, no. 2, pp. 262-268, 2011.

[19] M. V. Lazarini, E. R. Filho. Sensorless three-phase induction motor direct torque control using sliding mode control strategy laboratory set-up for motor speed control teaching. In Proceedings of the International Conference on Engineering Education, ICEE, Coimbra, Portugal, 2007.

[20] A. Levant. Robust exact differentiation via sliding mode technique. Automatica, vol. 34 no. 3, pp. 379-384, 1998. 
[21] S. Mahieddine-Mahmoud, M. Ouriagli, L. Chrifi-Alaoui, P. Bussy. Robust control of nonlinear systems with both matched and unmatched disturbances. In Proceedings of the 18th Mediterranean Conference on Control \& Automation, IEEE, Marrakech, pp. 1043-1048, 2010.

[22] W. M. Bessa. Some remarks on the boundedness and convergence properties of smooth sliding mode controllers. International Journal of Automation and Computing, vol.6, no. 2, pp. 154-158, 2009.

[23] M. Smaoui, X. Brun, D. Thomasset. A robust differentiatorcontroller design for an electropneumatic system. In Proceedings of the 44th IEEE Conference on Decision and Control, and the European Control Conference, IEEE, Seville, Spain, pp. 4385-4390, 2005.

[24] H. Charradi, A. Rabhi, K. Jamoussi, M. Ouali. A robust differentiator controller design for an induction motor. In Proceedings of International Conference on Sciences and Techniques of Automatic Control \& Computer Engineering, pp. 1-7, 2007.

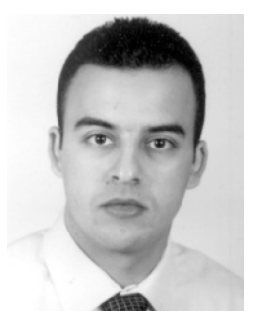

K. Jamoussi received his $\mathrm{Ph}$. D. degree in electrical engineering from National Engineering School of Sfax, Tunisia in 2012. Now, he is technologist in electrical genus and industrial computer sciences, in the High Institute of a Technological Studies. He is currently a researcher at Computer and Embedded System Laboratory (CES), National School of Engineers of Sfax, Tunisia.

His research interests include sliding mode control and control algorithm implementation on calculators.

E-mail: kais.jamoussi@yahoo.fr (Corresponding author)

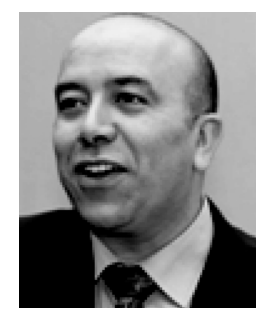

L. Chrifi-Alaoui received the Ph. D. degree in automatic control from the Centrale Lyon School, France. Since 1999, he has had a teaching position in automatic control in Aisne University Institute of Technology, France. From 2004 to 2010, he was the head of the Department of Electrical Engineering and Industrial Informatics, University of Picardie Jules Verne, France.

His research interests include linear and non-linear control theory (including sliding mode control, adaptive control, and robust control with applications to electric drive and mecatronics systems).
E-mail: larbi.alaoui@u-picardie.fr

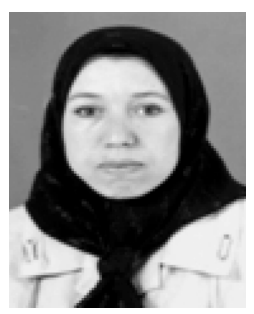

H. Benderradji received the B. Sc and M. Sc. degrees in electrical engineering from the Electrical Engineering Institute, Batna University, Algeria in 1993 and 2004, respectively. She joined the University of $\mathrm{Pi}-$ cardie, Jules Verne to prepare Ph. D. degree in electrical engineering, and she received the Ph. D. degree in electrical engineering from the Batna University, Algeria in 2013.After graduation, she joined the University of M'sila, Algeria, where she is an associate professor in the Electrical Engineering Institute.

Her research interests include advanced control techniques in the field of $\mathrm{AC}$ drives.

E-mail: h_benderradji@yahoo.fr

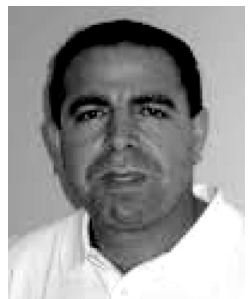

A. El Hajjaji received the Ph. D. degree in automatic control from the University of Picardie Jules Verne, France in 1993. From 1994 to 2003, he was an associate professor with the University of Picardie Jules Verne, where he is currently a full professor and the director of the Professional Institute of Electrical Engineering and Industrial Computing, and has been the head of the research team of control and vehicles with the Modelling, Information, and Systems Laboratory since 2001.

His research interests include fuzzy control, vehicle dynamics, fault-tolerant control, neural networks, maglev systems, and renewable energy.

E-mail: ahmed.hajjaji@u-picardie.fr

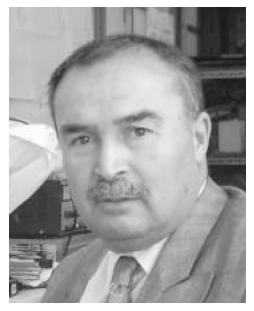

M. Ouali received his $\mathrm{Ph}$. D. degree in electrical engineering from University of Sfax, Tunisia in 1977. He became an associate professor at the University of Sfax, Tunisa in 1979. And he was a researcher at Electrical Motor Control and Power Electrical Networks Laboratory from 1985 to 2009. $\mathrm{He}$ is currently a researcher at Computer and Embedded System Laboratory. He is currently a professor in National School of Engineers of Sfax, Tunisia.

His research interests include robust control, motor control, and digital signal processor implementation.

E-mail: mohamed.ouali@enis.rnu.tn 